Mortality in people with psychotic disorders in Finland : A population-based 13-year follow-up study

Keinänen, Jaakko

2018-02

Keinänen , J , Mantere , O , Markkula , N , Partti , K, Perälä , J , Saarni , S I , Härkänen , T \& Suvisaari , J 2018 , ' Mortality in people with psychotic disorders in Finland : A population-based 13-year follow-up study ' , Schizophrenia Research , vol. 192 , pp. 113-118 . https://doi.org/10.1016/j.schres.2017.04.048

http://hdl.handle.net/10138/301091

https://doi.org/10.1016/j.schres.2017.04.048

publishedVersion

Downloaded from Helda, University of Helsinki institutional repository.

This is an electronic reprint of the original article.

This reprint may differ from the original in pagination and typographic detail.

Please cite the original version. 


\title{
Mortality in people with psychotic disorders in Finland: A population-based 13-year follow-up study
}

\author{
Jaakko Keinänen $^{\text {a,b,* }}$, Outi Mantere ${ }^{\text {b,c,d }}$, Niina Markkula ${ }^{\text {a,e }}$, Krista Partti ${ }^{\text {a,f }}$, Jonna Perälä a,b , Samuli I. Saarni ${ }^{\text {a,g }}$, \\ Tommi Härkänen ${ }^{\mathrm{h}}$, Jaana Suvisaari ${ }^{\mathrm{a}}$ \\ a National Institute for Health and Welfare, Department of Public Health Solutions, Mental Health Unit, P.O. Box 30, FIN-00271 Helsinki, Finland \\ ${ }^{\mathrm{b}}$ Department of Psychiatry, University of Helsinki and Helsinki University Hospital, P.O. Box 590, FIN-00029, HUS, Helsinki, Finland \\ c Department of Psychiatry, McGill University, 1033 Pine Avenue West, Montréal, QC H3A 1A1, Canada \\ d Bipolar Disorders Clinic, Douglas Mental Health University Institute, 6875 LaSalle Boulevard, Montréal, QC H4H 1R3, Canada \\ e Universidad del Desarrollo, Av. Plaza 680, San Carlos de Apoquindo, Las Condes, Santiago, Chile \\ ${ }^{\mathrm{f}}$ University of Helsinki, Doctoral Program in Clinical Research, P.O. Box 700, FIN-00029 HUS, Finland \\ ${ }^{g}$ Turku University Hospital and the University of Turku, P.O. Box 52, FIN-20521, Turku, Finland \\ ${ }^{\mathrm{h}}$ National Institute for Health and Welfare, Department of Public Health Solutions, Health Monitoring Unit, P.O. Box 30, FIN-00271, Helsinki, Finland
}

\section{A R T I C L E I N F O}

\section{Article history:}

Received 2 January 2017

Received in revised form 21 April 2017

Accepted 30 April 2017

Available online 9 May 2017

\section{Keywords:}

Mortality

Psychotic disorders

Somatic disease

Comorbidity

\begin{abstract}
A B S T R A C T
Objectives: We conducted a population based study aiming at finding predictors of mortality in psychotic disorders and evaluating the extent to which sociodemographic, lifestyle and health-related factors explain the excess mortality.

Methods: In a nationally representative sample of Finns aged 30-70 years $(n=5642)$, psychotic disorders were diagnosed using structured interviews and medical records in 2000-2001. Information on mortality and causes of death was obtained of those who died by the end of year 2013. Cox proportional hazards models were used to investigate the mortality risk.

Results: No people with affective psychoses $(n=36)$ died during the follow-up, thus the analysis was restricted to non-affective psychotic disorders (NAP) $(n=106)$. Adjusting for age and sex, NAP was statistically significantly associated with all-cause mortality (hazard ratio (HR) 2.99, 95\% CI 2.03-4.41) and natural-cause mortality (HR 2.81, 95\% CI 1.85-4.28). After adjusting for sociodemographic factors, health status, inflammation and smoking, the HR dropped to 2.11 (95\% CI 1.10-4.05) for all-cause and to 1.98 (95\% CI 0.94-4.16) for natural-cause mortality. Within the NAP group, antipsychotic use at baseline was associated with reduced HR for natural-cause mortality (HR 0.25, 95\% CI 0.07-0.96), and smoking with increased HR (HR 3.54, 95\% CI 1.07-11.69).

Conclusions: The elevated mortality risk in people with NAP is only partly explained by socioeconomic factors, lifestyle, cardio-metabolic comorbidities and inflammation. Smoking cessation should be prioritized in treatment of psychotic disorders. More research is needed on the quality of treatment of somatic diseases in people with psychotic disorders.
\end{abstract}

(C) 2017 Elsevier B.V. All rights reserved.

\section{Introduction}

Schizophrenia shortens the lifespan of those affected by up to 20 30 years (Olfson et al., 2015; Laursen et al., 2014). The excess mortality is mainly due to diseases and medical conditions, the leading causes being cardiovascular diseases, cancer, respiratory diseases and diabetes (Crump et al., 2013a; Suvisaari et al., 2013; Termorshuizen et al., 2013;

* Corresponding author at: National Institute for Health and Welfare, Department of Public Health Solutions, Mental Health Unit, P.O. Box 30, FIN-00271, Helsinki, Finland.

E-mail addresses: jaakko.keinanen@thl.fi (J. Keinänen),

outi.mantere@douglas.mcgill.ca (O. Mantere), niina.markkula@helsinki.fi (N. Markkula), krista.partti@thl.fi (K. Partti), jonna.perala@hus.fi (J. Perälä), samuli.saarni@tyks.fi

(S.I. Saarni), tommi.harkanen@thl.fi (T. Härkänen), jaana.suvisaari@thl.fi (J. Suvisaari).
Olfson et al., 2015). Studies indicate that during recent decades, the mortality gap between people with serious mental illness and the general population has at best narrowed only by a small amount (Wahlbeck et al., 2011), or has in fact increased (Saha et al., 2007; Olfson et al., 2015; Lumme et al., 2016; Osby et al., 2016).

Several factors predispose people with psychotic disorders to an increased risk of somatic diseases. Antipsychotic medication causes weight gain and increases the risk of metabolic syndrome, type 2 diabetes mellitus (T2DM), and cardiovascular disease (Foley and Morley, 2011). Sedentary lifestyle and poor diet, both common among people with psychotic disorders, further add to the metabolic burden (Dipasquale et al., 2013; Stubbs et al., 2016). Low income (McCallum et al., 2013) and living alone (Koskinen et al., 2007) are associated with excess mortality in the general population, and these factors may 
also contribute to excess mortality in people with psychotic disorders. Low-grade inflammation associated with schizophrenia (Potvin et al., 2008; Dickerson et al., 2013; Miller et al., 2014; Fernandes et al., 2016a) could be a peripheral marker of elevated mortality risk, as it is in the general population (Emerging Risk Factors Collaboration et al., 2010).

In people with psychotic disorders, the mortality from medical conditions is disproportionately high compared to morbidity (Crump et al., 2013a). This applies both to cardiovascular diseases and to cancer (Kisely et al., 2013). Both under-detection (Crump et al., 2013a) and poorer treatment (Kisely et al., 2013) of medical conditions contribute. In this study, we investigated mortality in non-affective psychosis (NAP) during a 13-year follow-up using data from the nationally representative Health 2000 Survey. We aimed to find predictors of mortality in NAP. Specifically, we wanted to see whether excess mortality in psychotic disorders can be explained by previously known sociodemographic and health-related factors. Further, we hypothesized that C-reactive protein (CRP) predicts mortality also in NAP but is not an independent predictor when somatic risk factors are controlled for.

\section{Methods}

\subsection{Study design}

The Finnish Health 2000 Survey (BRIF8901) sample consisted of 8028 persons aged 30 years or older. A nationally representative sample was achieved using a two-stage stratified cluster sampling procedure. The data were collected between September 2000 and June 2001. The survey consisted of an interview, a health examination and a shortened version of the Munich version of the Composite International Diagnostic Interview (M-CIDI) (Wittchen et al., 1998). Register information on the whole sample was collected to supplement interview and health examination data (Aromaa and Koskinen, 2004).

In the Psychoses in Finland study, we screened persons from the Health 2000 Survey sample for possible psychotic disorder and interviewed them using the research version of the Structured Clinical Interview for DSM-IV (SCID-I) (First et al., 2002). Persons were invited to participate in the SCID-I interview using the following screening criteria: (1) self-reported psychotic disorder, (2) a diagnosis of possible or definite psychotic disorder based on the physician's health examination, (3) psychotic or manic symptoms in the M-CIDI interview, (4) hospital treatment of any psychotic disorder according to the Hospital Discharge Register, (5) entitled to free outpatient antipsychotic medication, (6) disability pension due to psychotic disorder, and (7) mood-stabilizing medication use without a diagnosis of epilepsy or other neurological disease. Detailed description about sensitivity and specificity of these screens is reported in Perala et al. (2007).

The participation rate to the SCID-I was $63.4 \%$. In addition, we obtained all lifetime hospital and outpatient case records from psychiatric and primary care units for all Health 2000 participants. Using all available information, J.S., J.P., and S.I.S. made the final DSM-IV based diagnoses and assessed whether people had a current psychiatric treatment contact (Perala et al., 2007).

The Health 2000 Survey and the Psychoses in Finland study were approved by the Ethics Committees of the National Public Health Institute (the National Institute for Health and Welfare since 2009) and the Hospital District of Helsinki and Uusimaa. Participants gave a written informed consent after having received a complete description of the study.

\subsection{Study population}

In the analysis, we excluded (1) persons aged 70 years and older to avoid confounding our analysis with the high mortality of the oldest age groups and (2) persons with substance-induced psychotic disorders or psychotic disorders due to a general medical condition. The original study sample included 6334 persons aged under 70 years, from whom $5642(89.1 \%)$ had participated in the Health 2000 study and were followed up in the current study. Weights were used to correct for nonresponse, as described in Section 2.5.

In this study, we investigated people with NAP, including schizophrenia, schizophreniform disorder, schizoaffective disorder, delusional disorder, brief psychotic disorder and psychotic disorder not otherwise specified. Descriptive data are reported from people with affective psychosis (bipolar I disorder or major depressive disorder with psychotic features) as well, but a predictor analysis was not possible due to no deaths in this group in people aged under 70 years.

\subsection{Predictors of mortality}

\subsubsection{Antipsychotic medication}

Participants reported their current medication at baseline and that information was used to code the antipsychotic medication use. Participants had brought their prescriptions or medications to the interview to assist in recording medication use.

\subsubsection{Socioeconomic factors}

Marital status was coded as married or cohabiting, or unmarried (divorced, never-married or widowed) at baseline. The registers of the Finnish Tax Administration were used to determine family income, adjusted for family size and divided into quintiles.

\subsubsection{Lifestyle and health variables}

Body mass index (BMI) was calculated as weight $(\mathrm{kg})$ divided by the square of height $(\mathrm{m})$. Participants were categorized as current smokers or nonsmokers based on their own report at baseline.

\subsubsection{Chronic somatic diseases}

T2DM was diagnosed according to the WHO 1999 criteria (World Health Organization Expert Committee, 1999). The diagnostic procedure for possible or definite coronary heart disease (CHD) based on health examination, electrocardiogram, and register data as described in Kattainen et al. (2006).

Diagnosis of metabolic syndrome was based on The National Cholesterol Education Program's Adult Treatment Panel III criteria (Expert Panel on Detection, Evaluation, and Treatment of High Blood Cholesterol in Adults, 2001).

The detailed diagnostic process for these conditions and for the laboratory and other measures are described in supplementary methods.

\subsubsection{Low-grade inflammation}

Low-grade inflammation was analyzed using a categorical variable as measured by the highest quintile of CRP concentration $(2.43 \mathrm{mg} / \mathrm{L})$ as a cut-off.

\subsection{Information on mortality and causes of death}

Information on mortality up to December 31st 2013 and causes of death were obtained from the Cause of Death statistics kept by Statistics Finland. The statistics contain data from death certificates completed either by the treating physician or by the physician who performed the autopsy. The medicolegal autopsy rate in Finland is exceptionally high (Lunetta et al., 2007), and the Cause of Death statistics is considered reliable.

Causes of death were classified into natural causes (ICD-10 A00R99), including alcohol-related diseases and accidental poisoning by alcohol (F10, G312, G4051, G621, G721, I426, K292, K70, K852, K860, 0354, P043, Q860, X45), and unnatural causes, including suicide (X60-X84, Y870) and other unnatural causes (V01-X44, X46-X59, X85-Y86, Y871-Y89). 


\subsection{Statistical analyses}

Between-group comparisons of clinical and sociodemographic variables were performed with Pearson's $\chi^{2}$, the Fisher exact test, the Student's $t$-test or the Mann-Whitney U test. P $<0.05$ was used to denote statistical significance.

We used SUDAAN software, Release 11.0.1, in statistical analysis, taking into account the two-stage cluster sampling design. Sampling design was taken into account in all statistical analyses, and post-stratification weights were applied to adjust for non-response in the baseline study. Analyses within the psychosis group, as well as the checking of the proportional hazards assumption for the survival analysis carried out in SUDAAN, were conducted using SAS software, Version 9.3 for Windows.

To investigate the effect of different variables on mortality, seven Cox regression models were built using SUDAAN's SURVIVAL procedure. All models were adjusted for age and sex. Model I included the diagnosis of NAP, model II NAP and antipsychotic medication use. In models III-VI, we added one significant group of explanatory variables to model II that could potentially contribute to the excess mortality in NAP: chronic inflammation (CRP) in model III, marital status and income in model IV, lifestyle-related factors (BMI and smoking) in model V, and chronic diseases (T2DM, metabolic syndrome and CHD) in model VI. In model VII, all these variables were entered simultaneously in the model. For the final model, we checked the proportional hazards assumption by running the same model with SAS's PHREG procedure, and the Kolmogorov-type supremum test indicated that the proportional hazards assumption held for all variables. These analyses were done separately for all-cause mortality and for mortality from diseases and medical conditions.

Factors predicting mortality in people with psychotic disorder were analyzed with Cox's proportional hazards model, using SAS's PHREG procedure. Since there were only 106 people with NAP, sampling design was not taken into account in these analyses. The same variables were used as in model VII for the total sample, with the exception of CHD due to the small number of cases. This analysis was done separately for all-cause mortality and for mortality from diseases and medical conditions.

\section{Results}

Demographic and clinical characteristics in the NAP group, in the affective psychosis group, and in the group without psychosis diagnosis are shown in Table 1. In the affective psychosis group, there were no deaths during the follow-up and thus, in the analysis of predictors of mortality, we focused on NAP. Among participants with NAP, there were altogether 25 deaths (Supplementary Table 1 ). Deaths by natural causes made up $84 \%(21 / 25)$ of the total number of deaths in the NAP group, and cancer (32\%) and cardiovascular disease (24\%) were the most common causes of death.

In the NAP group, those who died during the follow-up were older, had a higher prevalence of T2DM, and were more often living alone than those who survived (Table 2).

Table 3 presents the mortality hazard ratios (HR) from Cox regression models during the follow-up adjusted with seven different sets of variables. Diagnosis of NAP was a significant predictor of all-cause mortality even after adjusting for all sociodemographic and health-related variables (HR 2.11, 95\% CI 1.10-4.05).

In the Cox model for natural-cause mortality, the mortality HR for NAP was from 2.0 to 2.8, depending on the adjusting variables (Table 4). When adjusting for all the relevant variables (Model VII), the mortality HR for NAP lost its statistical significance (HR 1.98, 95\% CI 0.94-4.16). In all the other models, NAP was a significant predictor for natural-cause mortality. Full models are presented in Supplementary Tables 2 and 3.

Table 1

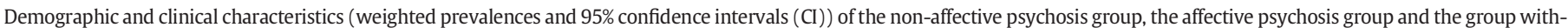
out psychosis diagnosis at study baseline.

\begin{tabular}{|c|c|c|c|}
\hline Characteristic & Non-affective psychosis $\left(\mathrm{n}=106^{\mathrm{a}}\right), \%(95 \% \mathrm{CI})$ & Affective psychosis $\left(\mathrm{n}=36^{\mathrm{a}}\right)$, \% $(95 \% \mathrm{CI})$ & No psychosis $\left(\mathrm{n}=5500^{\mathrm{a}}\right), \%(95 \% \mathrm{CI})$ \\
\hline \multicolumn{4}{|l|}{ Age } \\
\hline $30-40$ & $17.5(11.4-25.9)$ & $18.1(8.9-33.3)$ & $29.1(27.9-30.3)$ \\
\hline$>40-50$ & $32.6(24.3-42.1)$ & $39.8(25.1-56.6)$ & $28.9(27.7-30.1)$ \\
\hline$>50-60$ & $32.1(23.9-41.6)$ & $25.8(14.1-42.3)$ & $26.3(25.1-27.5)$ \\
\hline$>60-70$ & $17.8(11.3-27.0)$ & $16.4(7.6-31.9)$ & $15.7(14.7-16.8)$ \\
\hline \multicolumn{4}{|l|}{ Sex } \\
\hline Male & $42.5(32.7-52.9)$ & $63.2(46.7-77.1)$ & $49.8(48.5-51.2)$ \\
\hline Female & $57.5(47.2-67.3)$ & $36.8(22.9-53.3)$ & $50.2(48.9-51.5)$ \\
\hline Married or cohabiting & $33.9^{\mathrm{b}}(25.7-43.3)$ & $59.3(42.5-74.2)$ & $74.2 \%^{\mathrm{c}}(73.0-75.5)$ \\
\hline Lowest income quintile & $50.5(40.6-60.4)$ & $22.0(11.3-38.4)$ & $18.5(17.3-19.8)$ \\
\hline Antipsychotic medication & $58.1(49.0-66.7)$ & $29.9(16.3-48.3)$ & $0.7(0.5-1.0)$ \\
\hline \multicolumn{4}{|l|}{ Body mass index } \\
\hline$<25$ & $31.2^{\mathrm{d}}(23.2-40.4)$ & $25.1(14.0-40.8)$ & $38.9^{\mathrm{e}}(37.6-40.3)$ \\
\hline $25-30$ & $27.4^{\mathrm{d}}(19.6-36.9)$ & $45.9(31.3-61.4)$ & $39.8^{\mathrm{e}}(38.5-41.1)$ \\
\hline$>30$ & $41.4^{\mathrm{d}}(32.2-51.3)$ & $29.0(16.1-46.4)$ & $21.3^{\mathrm{e}}(20.3-22.4)$ \\
\hline Smoking & $40.0^{f}(30.6-50.2)$ & $29.0(16.3-46.0)$ & $26.4^{\mathrm{g}}(25.3-27.5)$ \\
\hline High C-reactive protein ${ }^{\mathrm{h}}$ & $43.6^{\mathrm{i}}(32.8-54.9)$ & $18.4^{\mathrm{j}}(8.2-36.1)$ & $19.6^{\mathrm{k}}(18.5-20.7)$ \\
\hline Coronary heart disease & $4.8(2.1-10.6)$ & $3.1(0.4-19.2)$ & $5.3(4.6-6.0)$ \\
\hline Metabolic syndrome & $46.4^{1}(35.9-57.3)$ & $24.1^{\mathrm{m}}(12.4-41.5)$ & $27.6^{\mathrm{n}}(26.2-29.0)$ \\
\hline Type 2 diabetes mellitus & $18.0(11.9-26.3)$ & $2.7(0.4-16.8)$ & $4.2(3.7-4.7)$ \\
\hline
\end{tabular}

\footnotetext{
a Except where otherwise indicated.

b $\mathrm{n}=105$.

c $\mathrm{n}=5483$.

d $\mathrm{n}=103$.

e $\mathrm{n}=5470$.

${ }^{\mathrm{f}} \mathrm{n}=105$.

g $\mathrm{n}=548$.

h Highest C-reactive protein concentration quintile (CRP $>2.43 \mathrm{mg} / \mathrm{L}$ ).

${ }^{\mathrm{i}} \mathrm{n}=87$.

$\mathrm{j} n=32$.

$\mathrm{k} \mathrm{n}=5097$.

${ }^{1} \mathrm{n}=99$.

m $\mathrm{n}=34$.

$\mathrm{n} n=5268$.
} 
Table 2

Comparison of demographic and clinical characteristics between those who died during the follow-up and those who survived in the non-affective psychosis group.

\begin{tabular}{|c|c|c|c|}
\hline Characteristic & Dead $\%(n=25 / 106,23.6 \%)$ & Alive $\%(n=81 / 106,76.4 \%)$ & Statistics \\
\hline Sex (\% females) & $48.0(12 / 25)$ & $38.3(31 / 81)$ & $\chi^{2}=0.75, p=0.39$ \\
\hline Age at baseline (mean, $\mathrm{SD}$ ) & 55.9, SD 9.3 & 48.8, SD 10.0 & $\mathrm{t}=-3.13, \mathrm{p}=0.002$ \\
\hline Married or cohabiting & $16.0(4 / 25)$ & $40.0(32 / 80)$ & $\chi^{2}=4.87, \mathrm{p}=0.03$ \\
\hline Active treatment contact & $65.2(15 / 23)$ & $74.0(54 / 73)$ & $\chi^{2}=0.66, p=0.42$ \\
\hline C-reactive protein (mg/l) (median, min-max) & $2.17,0.00-28.3^{\mathrm{a}}$ & $1.47,0.00-16.0^{\mathrm{b}}$ & $\mathrm{U}=751.50, \mathrm{p}=0.17$ \\
\hline Antipsychotic use & $60.0(15 / 25)$ & $58.0(47 / 81)$ & $\chi^{2}=0.03, \mathrm{p}=0.86$ \\
\hline Body mass index $\left(\mathrm{kg} / \mathrm{m}^{2}\right)$ & $28.6, \operatorname{SD} 5.28^{\mathrm{c}}$ & 28.9, SD $6.10^{d}$ & $\mathrm{t}=0.22, \mathrm{p}=0.83$ \\
\hline Proportion diagnosed with T2DM & $36.0(9 / 25)$ & $12.3(10 / 81)$ & $\mathrm{p}=0.014$ (Fisher's exact test) \\
\hline Proportion diagnosed with CHD & $4.0(1 / 25)$ & $4.9(4 / 81)$ & $\mathrm{p}=1.000($ Fisher's exact test $)$ \\
\hline Metabolic syndrome & $62.5(15 / 24)$ & $41.3(31 / 75)$ & $\chi^{2}=3.28, p=0.07$ \\
\hline Smoking & $56.0(14 / 25)$ & $35.0(28 / 80)$ & $\chi^{2}=3.50, p=0.06$ \\
\hline Lowest income quintile & $56.0(14 / 25)$ & $49.4(40 / 81)$ & $\chi^{2}=0.34, p=0.56$ \\
\hline
\end{tabular}

Abbreviations: $\chi^{2}$, Pearson's chi square test; t, Student's $t$-test; U, Mann-Whitney U test; T2DM, type 2 diabetes mellitus; CHD, coronary heart disease.

a Information available $\mathrm{n}=18$.

b Information available $\mathrm{n}=69$.

c Information available $\mathrm{n}=24$.

d Information available $\mathrm{n}=79$.

Within the NAP group, antipsychotic use at baseline was associated with reduced HR for natural-cause mortality (HR 0.25 , 95\% CI 0.07 0.96), and smoking with increased HR (HR 3.54, 95\% CI 1.07-11.69), whereas none of the variables was a significant predictor of all-cause mortality (Supplementary Tables 4 and 5 ). A separate model was not done for mortality from unnatural causes because of their low frequency in the NAP group.

\section{Discussion}

In this study, we found an almost 3-fold increase in the mortality HR for those diagnosed with NAP during a 13-year follow-up compared to the general population. The HR decreased to 2.1 when adjusting for all relevant sociodemographic and lifestyle variables and for somatic diseases. The increased mortality of people diagnosed with NAP was mostly due to natural causes. Accidents and suicide accounted for $16 \%$ of total number of deaths in the NAP group. Smoking increased the mortality HR for natural-cause mortality in the NAP group while antipsychotic use decreased it.

We observed an increased mortality HR in people with NAP in accordance with previous literature (Olfson et al., 2015; Suvisaari et al., 2013). When smoking, obesity, socioeconomic factors, chronic conditions and inflammation were taken into account, the HR associated with NAP dropped from three to two, suggesting that these factors explain some but not all excess mortality related to NAP. Worse quality of treatment may be one contributing factor. In previous studies, worse quality of treatment has been particularly evident for cardiovascular diseases and cancer, which were the most common causes of death in the NAP group. For example, a previous Finnish study found that patients with NAP with CHD were much less likely to receive coronary revascularization than other people with CHD (Manderbacka et al., 2012). Studies from other countries have found poorer quality of cancer treatment in people with psychotic disorders (Bergamo et al., 2014;
Ishikawa et al., 2016) and a similar observation has been made in Finland (K. Manderbacka, personal communication). Poor participation in cancer screenings may be an additional factor contributing to increased mortality from cancer (Weinstein et al., 2016).

Within the NAP group, smoking was significantly associated with excess mortality risk, which is consistent with previous studies (Dickerson et al., 2016; Tam et al., 2016).

The low prevalence of smoking in Finland as compared to several other countries further stresses its importance for excess mortality. Unfortunately, smoking cessation is still often neglected in clinical practice, although there are effective ways to support quitting (Stubbs et al., 2015). Our results highlight the importance of smoking prevention and cessation to decrease the mortality of people with serious mental illness.

Recent meta-analyses show that CRP is higher in psychotic disorders than in the general population, and this has been used as evidence for a systemic inflammatory disorder (Fernandes et al., 2016a; Fernandes et al., 2016b). Also in our study, CRP was elevated in the NAP group. Consistent with previous studies (Emerging Risk Factors Collaboration et al., 2010) CRP was a risk factor for excess mortality in our sample in the total population. The NAP group showed a trend towards higher CRP concentration for those who died during the follow-up. However, CRP was not an independent predictor of mortality, although the modest power does not allow us to exclude any independent effect. Given the sampling at age of 30 or later, the data are not suitable for detecting possible systemic inflammatory processes at onset of a psychotic disorder.

Antipsychotic treatment at baseline in people with NAP was associated with lower mortality risk. In our previous study, antipsychotic use was associated with elevated mortality risk in people who did not have a psychotic disorder but not in people with psychotic disorder (Suvisaari et al., 2013). Only about 60\% of persons with NAP were using antipsychotics at baseline, and slightly more had an active psychiatric treatment contact. The low rate of self-reported antipsychotic use

Table 3

Cox proportional hazards model for all-cause mortality in people diagnosed with non-affective psychosis $(\mathrm{n}=106)$ adjusted with a different set of variables in each model.

\begin{tabular}{|c|c|c|c|c|c|c|c|c|c|c|c|c|c|}
\hline $\begin{array}{l}\text { Model I } \\
\text { HR }(95 \% \text { CI })\end{array}$ & $\mathrm{p}$ & $\begin{array}{l}\text { Model II } \\
\text { HR }(95 \% \text { CI })\end{array}$ & $\mathrm{p}$ & $\begin{array}{l}\text { Model III }{ }^{\mathrm{C}} \\
\text { HR }(95 \% \mathrm{CI})\end{array}$ & $\mathrm{p}$ & $\begin{array}{l}\text { Model IV } \\
\text { HR }(95 \% \text { CI })\end{array}$ & $\mathrm{p}$ & $\begin{array}{l}\text { Model V } \\
\text { HR }(95 \% \text { CI })\end{array}$ & $\mathrm{p}$ & $\begin{array}{l}\text { Model VI } \\
\text { HR }(95 \% \text { CI })\end{array}$ & $\mathrm{p}$ & $\begin{array}{l}\text { Model VII } \\
\text { HR }(95 \% \text { CI })\end{array}$ & $\mathrm{p}$ \\
\hline $\begin{array}{l}2.99 \\
(2.03-4.41)\end{array}$ & $<0.001$ & $\begin{array}{l}2.44 \\
(1.44-4.14)\end{array}$ & $<0.001$ & $\begin{array}{l}2.58 \\
(1.38-4.81)\end{array}$ & 0.0029 & $\begin{array}{l}2.22 \\
(1.30-3.80)\end{array}$ & 0.0035 & $\begin{array}{l}2.28 \\
(1.26-4.11)\end{array}$ & 0.0063 & $\begin{array}{l}2.41 \\
(1.33-4.39)\end{array}$ & 0.0039 & $\begin{array}{l}2.11 \\
(1.10-4.05)\end{array}$ & 0.0253 \\
\hline
\end{tabular}

Abbreviations: HR, hazard ratio; CI, confidence interval; p, p-value.

a Adjusted for sex and age.

b Adjusted in addition for antipsychotic use.

c Adjusted in addition for C-reactive protein concentration.

d Adjusted for (b), marital status and income.

e Adjusted for (b), body mass index and smoking status.

${ }^{f}$ Adjusted for (b), type 2 diabetes mellitus, metabolic syndrome and coronary heart disease.

$g$ Adjusted for all variables in a-f. 
Table 4

Cox proportional hazards model for natural-cause mortality in people diagnosed with non-affective psychosis $(\mathrm{n}=106)$ adjusted with a different set of variables in each model.

\begin{tabular}{|c|c|c|c|c|c|c|c|c|c|c|c|c|c|}
\hline Model I ${ }^{\mathrm{a}}$ & & Model II ${ }^{\mathrm{b}}$ & & Model III ${ }^{\mathrm{c}}$ & & Model IV ${ }^{\mathrm{d}}$ & & Model V & & Model VI ${ }^{\mathrm{f}}$ & & Model VII ${ }^{\mathrm{g}}$ & \\
\hline HR (95\% CI) & $\mathrm{p}$ & HR (95\% CI) & $\mathrm{p}$ & HR (95\% CI) & $\mathrm{p}$ & $\mathrm{HR}(95 \% \mathrm{CI})$ & $\mathrm{p}$ & $\mathrm{HR}(95 \% \mathrm{CI})$ & $\mathrm{p}$ & HR (95\% CI) & $\mathrm{p}$ & HR (95\% CI) & $\mathrm{p}$ \\
\hline $\begin{array}{l}2.81 \\
\quad(1.85-4.28)\end{array}$ & $<0.001$ & $\begin{array}{l}2.29 \\
(1.28-4.10)\end{array}$ & 0.0055 & $\begin{array}{l}2.44 \\
(1.21-4.92)\end{array}$ & 0.0125 & $\begin{array}{l}2.10 \\
(1.16-3.80)\end{array}$ & 0.0142 & $\begin{array}{l}2.09 \\
(1.09-4.03)\end{array}$ & 0.0273 & $\begin{array}{l}2.23 \\
(1.14-4.38)\end{array}$ & 0.0198 & $\begin{array}{l}1.98 \\
(0.94-4.16)\end{array}$ & 0.0704 \\
\hline
\end{tabular}

Abbreviations: $\mathrm{HR}$, hazard ratio; $\mathrm{CI}$, confidence interval; $\mathrm{p}$, p-value.

a Adjusted for sex and age.

b Adjusted in addition for antipsychotic use.

c Adjusted in addition for C-reactive protein concentration.

d Adjusted for (b), marital status and income.

e Adjusted for (b), body mass index and smoking status.

f Adjusted for (b), type 2 diabetes mellitus, metabolic syndrome and coronary heart disease.

$\mathrm{g}$ Adjusted for all variables in a-f.

may reflect the typically low adherence to medication in people with psychotic disorders (Velligan et al., 2009). While diagnoses of psychotic disorders were lifetime diagnoses and included disorders that were in remission and no longer required treatment, treatment drop-outs were also common (Suvisaari et al., 2009). Therefore, the protective effect of antipsychotic treatment may indicate the importance of treatment adherence in general.

The main strengths of this study are the large and representative population-based sample, high participation rate and diagnostic screening using many sources of information. We had extensive measurements of somatic and sociodemographic factors from the baseline. Information on causes of death in Finland is reliable.

A limitation of the study is that during the follow-up, we had no information on mental health, antipsychotic use or other potential factors affecting mortality. Another limitation is the small sample size in survival analyses done within the NAP group, which resulted in wide confidence intervals. It was somewhat surprising to recognize that no deaths were detected within the study period among patients with a psychotic mood disorder. Previous studies have reported an increased mortality risk for patients with mood disorders as compared to the general population (Harris and Barraclough, 1997; Roshanaei-Moghaddam and Katon, 2009; Crump et al., 2013b), but to a lesser extent than in schizophrenia (Chesney et al., 2014; Kessing et al., 2015; Walker et al., 2015). However, we have previously observed in this sample that in contrast to NAP, people with affective psychoses did not have elevated risk of T2DM, metabolic syndrome or CHD (Suvisaari et al., 2007; Suvisaari et al., 2008; Suvisaari et al., 2010). The difference to other studies in mood disorders might partly be explained by the long duration of follow-up (Walker et al., 2015), differences in received somatic treatment (Manderbacka et al., 2012) and the fact that the sampling was done for people 30 years and older excluding thus those who committed suicide at earlier phase of illness.

\section{Conclusions}

People with non-affective psychosis have elevated mortality risk, which is only partly explained by socioeconomic factors, lifestyle, cardiometabolic comorbidities and inflammation. Smoking was the single most important factor contributing to mortality within the NAP group. More research is needed on the quality of treatment of somatic diseases in people with psychotic disorders. Since smoking cessation (Stubbs et al., 2015; Tidey and Miller, 2015) and personalized treatment of diabetes (Larsen et al., 2016) are effective interventions to reduce mortality, they should be prioritized in the treatment of people with psychotic disorders.

\section{Conflict of interest}

Jaakko Keinänen owns shares in pharmaceutical company Orion. All other authors declare that they have no conflicts of interest.

\section{Contributors}

Jaana Suvisaari, Jonna Perälä and Samuli Saarni designed the study protocol of the Psychoses in Finland study and were responsible for diagnostic assessment of psychotic disorders. Jaakko Keinänen, Jaana Suvisaari and Outi Mantere designed the study protocol of the mortality risk assessment, managed the literature searches and analyses and wrote the first draft of the manuscript. Tommi Härkänen, Jaana Suvisaari and Jaakko Keinänen undertook the statistical analyses. All authors contributed to and have accepted the final manuscript.

\section{Role of the funding source}

The funding organization had no role in the design and conduct of the study; collection, management, analysis, and interpretation of the data; and preparation, review, or approval of the manuscript.

\section{Acknowledgements}

This study was funded by Academy of Finland Grants 129434 and 278171, a Sigrid Juselius Foundation grant (Jaana Suvisaari) and by the Helsinki University Central Hospital (Funding Reference Numbers: TYH2013332 and TYH2014228, Outi Mantere).

\section{Appendix A. Supplementary data}

Supplementary data to this article can be found online at http://dx. doi.org/10.1016/j.schres.2017.04.048.

\section{References}

Aromaa, A., Koskinen, S., 2004. Health and Functional Capacity in Finland. Baseline Results of the Health 2000 Health Examination Survey.

Bergamo, C., Sigel, K., Mhango, G., Kale, M., Wisnivesky, J.P., 2014. Inequalities in lung cancer care of elderly patients with schizophrenia: an observational cohort study. Psychosom. Med. 76 (3), 215-220.

Chesney, E., Goodwin, G.M., Fazel, S., 2014. Risks of all-cause and suicide mortality in mental disorders: a meta-review. World Psychiatry 13 (2), 153-160.

Crump, C., Winkleby, M.A., Sundquist, K., Sundquist, J., 2013a. Comorbidities and mortality in persons with schizophrenia: a Swedish national cohort study. Am. J. Psychiatry 170 (3), 324-333.

Crump, C., Sundquist, K., Winkleby, M.A., Sundquist, J., 2013b. Comorbidities and mortality in bipolar disorder: a Swedish national cohort study. JAMA Psychiatry 70 (9), 931-939.

Dickerson, F., Stallings, C., Origoni, A., Vaughan, C., Khushalani, S., Yang, S., Yolken, R., 2013. C-reactive protein is elevated in schizophrenia. Schizophr. Res. 143 (1), 198-202.

Dickerson, F., Origoni, A., Schroeder, J., Schweinfurth, L.A., Stallings, C., Savage, C.L., Katsafanas, E., Banis, M., Khushalani, S., Yolken, R., 2016. Mortality in schizophrenia and bipolar disorder: clinical and serological predictors. Schizophr. Res. 170 (1), 177-183.

Dipasquale, S., Pariante, C.M., Dazzan, P., Aguglia, E., McGuire, P., Mondelli, V., 2013. The dietary pattern of patients with schizophrenia: a systematic review. J. Psychiatr. Res. 47 (2), 197-207.

Emerging Risk Factors CollaborationKaptoge, S., Di Angelantonio, E., Lowe, G., Pepys, M.B., Thompson, S.G., Collins, R., Danesh, J., 2010. C-reactive protein concentration and risk of coronary heart disease, stroke, and mortality: an individual participant meta-analysis. Lancet 375 (9709), 132-140.

Expert Panel on Detection, Evaluation, and Treatment of High Blood Cholesterol in Adults, 2001. Executive summary of the third report of the national cholesterol education program (NCEP) expert panel on detection, evaluation, and treatment of high blood cholesterol in adults (adult treatment panel III). JAMA 285 (19), 2486-2497.

Fernandes, B.S., Steiner, J., Bernstein, H.G., Dodd, S., Pasco, J.A., Dean, O.M., Nardin, P., Goncalves, C.A., Berk, M., 2016a. C-reactive protein is increased in schizophrenia but is not altered by antipsychotics: meta-analysis and implications. Mol. Psychiatry 21 (4), 554-564.

Fernandes, B.S., Steiner, J., Molendijk, M.L., Dodd, S., Nardin, P., Goncalves, C.A., Jacka, F., Kohler, C.A., Karmakar, C., Carvalho, A.F., Berk, M., 2016b. C-reactive protein 
concentrations across the mood spectrum in bipolar disorder: a systematic review and meta-analysis. Lancet Psychiatry.

First, M.B., Spitzer, R.L., Gibbon, M., Williams, J.B.W., 2002. Structured Clinical Interview for DSM-IV-TR Axis I Disorders, Research Version, Patient Edition. (SCID-I/P). New York State Psychiatric Institute: Biometrics Research Department, New York, NY.

Foley, D.L., Morley, K.I., 2011. Systematic review of early cardiometabolic outcomes of the first treated episode of psychosis. Arch. Gen. Psychiatry 68 (6), 609-616.

Harris, E.C., Barraclough, B., 1997. Suicide as an outcome for mental disorders. A metaanalysis. Br. J. Psychiatry 170, 205-228.

Ishikawa, H., Yasunaga, H., Matsui, H., Fushimi, K., Kawakami, N., 2016. Differences in cancer stage, treatment and in-hospital mortality between patients with and without schizophrenia: retrospective matched-pair cohort study. Br. J. Psychiatry 208 (3), 239-244.

Kattainen, A., Salomaa, V., Harkanen, T., Jula, A., Kaaja, R., Kesaniemi, Y.A., Kahonen, M., Moilanen, L., Nieminen, M.S., Aromaa, A., Reunanen, A., 2006. Coronary heart disease: from a disease of middle-aged men in the late 1970s to a disease of elderly women in the 2000s. Eur. Heart J. 27 (3), 296-301.

Kessing, L.V., Vradi, E., McIntyre, R.S., Andersen, P.K., 2015. Causes of decreased life expectancy over the life span in bipolar disorder. J. Affect. Disord. 180, 142-147.

Kisely, S., Crowe, E., Lawrence, D., 2013. Cancer-related mortality in people with mental illness. JAMA Psychiat. 70 (2), 209-217.

Koskinen, S., Joutsenniemi, K., Martelin, T., Martikainen, P., 2007. Mortality differences according to living arrangements. Int. J. Epidemiol. 36 (6), 1255-1264.

Larsen, J.R., Siersma, V.D., Davidsen, A.S., Waldorff, F.B., Reventlow, S., de Fine Olivarius, N., 2016. The excess mortality of patients with diabetes and concurrent psychiatric illness is markedly reduced by structured personal diabetes care: a 19-year follow up of the randomized controlled study diabetes care in general practice (DCGP). Gen. Hosp. Psychiatry 38, 42-52.

Laursen, T.M., Nordentoft, M., Mortensen, P.B., 2014. Excess early mortality in schizophrenia. Annu. Rev. Clin. Psychol. 10, 425-448.

Lumme, S., Pirkola, S., Manderbacka, K., Keskimaki, I., 2016. Excess mortality in patients with severe mental disorders in 1996-2010 in Finland. PLoS One 11 (3), e0152223.

Lunetta, P., Lounamaa, A., Sihvonen, S., 2007. Surveillance of injury-related deaths: medicolegal autopsy rates and trends in Finland. Inj. Prev. 13 (4), 282-284.

Manderbacka, K., Arffman, M., Sund, R., Haukka, J., Keskimaki, I., Wahlbeck, K., 2012. How does a history of psychiatric hospital care influence access to coronary care: a cohort study. BMJ Open 2 (2) (e000831-2012-000831. Print 2012).

McCallum, A.K., Manderbacka, K., Arffman, M., Leyland, A.H., Keskimaki, I., 2013. Socioeconomic differences in mortality amenable to health care among Finnish adults 1992 2003: 12 year follow up using individual level linked population register data. BMC Health Serv. Res. 13 (3-6963-13-3).

Miller, B.J., Culpepper, N., Rapaport, M.H., 2014. C-reactive protein levels in schizophrenia: a review and meta-analysis. Clin. Schizophr. Relat. Psychoses 7 (4), 223-230.

Olfson, M., Gerhard, T., Huang, C., Crystal, S., Stroup, T.S., 2015. Premature mortality among adults with schizophrenia in the United States. JAMA Psychiat. 72 (12), 1172-1181.

Osby, U., Westman, J., Hallgren, J., Gissler, M., 2016. Mortality trends in cardiovascular causes in schizophrenia, bipolar and unipolar mood disorder in Sweden 19872010. Eur. J. Pub. Health.

Perala, J., Suvisaari, J., Saarni, S.I., Kuoppasalmi, K., Isometsa, E., Pirkola, S., Partonen, T. Tuulio-Henriksson, A., Hintikka, J., Kieseppa, T., Harkanen, T., Koskinen, S., Lonnqvist, J., 2007. Lifetime prevalence of psychotic and bipolar I disorders in a general population. Arch. Gen. Psychiatry 64 (1), 19-28.

Potvin, S., Stip, E., Sepehry, A.A., Gendron, A., Bah, R., Kouassi, E., 2008. Inflammatory cytokine alterations in schizophrenia: a systematic quantitative review. Biol. Psychiatry 63 (8), 801-808.
Roshanaei-Moghaddam, B., Katon, W., 2009. Premature mortality from general medical illnesses among persons with bipolar disorder: a review. Psychiatr. Serv. 60 (2), 147-156.

Saha, S., Chant, D., McGrath, J., 2007. A systematic review of mortality in schizophrenia: is the differential mortality gap worsening over time? Arch. Gen. Psychiatry 64 (10), 1123-1131.

Stubbs, B., Vancampfort, D., Bobes, J., De Hert, M., Mitchell, A.J., 2015. How can we promote smoking cessation in people with schizophrenia in practice? A clinical overview. Acta Psychiatr. Scand. 132 (2), 122-130.

Stubbs, B., Williams, J., Gaughran, F., Craig, T., 2016. How sedentary are people with psychosis? A systematic review and meta-analysis. Schizophr. Res. 171 (1-3), 103-109.

Suvisaari, J.M., Saarni, S.I., Perala, J., Suvisaari, J.V., Harkanen, T., Lonnqvist, J., Reunanen, A 2007. Metabolic syndrome among persons with schizophrenia and other psychotic disorders in a general population survey. J. Clin. Psychiatry 68 (7), 1045-1055.

Suvisaari, J., Perala, J., Saarni, S.I., Harkanen, T., Pirkola, S., Joukamaa, M., Koskinen, S. Lonnqvist, J., Reunanen, A., 2008. Type 2 diabetes among persons with schizophrenia and other psychotic disorders in a general population survey. Eur. Arch. Psychiatry Clin. Neurosci. 258 (3), 129-136.

Suvisaari, J., Perälä, J., Saarni, S., Juvonen, H., Tuulio-Henriksson, A., Lönnqvist, J., 2009. The epidemiology and descriptive and predictive validity of DSM-IV delusional disorder and subtypes of schizophrenia. Clin. Schizophr. Relat. Psychoses 2 (4), 289-297.

Suvisaari, J., Perala, J., Saarni, S.I., Kattainen, A., Lonnqvist, J., Reunanen, A., 2010. Coronary heart disease and cardiac conduction abnormalities in persons with psychotic disorders in a general population. Psychiatry Res. 175 (1-2), 126-132.

Suvisaari, J., Partti, K., Perala, J., Viertio, S., Saarni, S.E., Lonnqvist, J., Saarni, S.I., Harkanen, T., 2013. Mortality and its determinants in people with psychotic disorder Psychosom. Med. 75 (1), 60-67.

Tam, J., Warner, K.E., Meza, R., 2016. Smoking and the reduced life expectancy of individuals with serious mental illness. Am. J. Prev. Med.

Termorshuizen, F., Wierdsma, A.I., Smeets, H.M., Visser, E., Drukker, M., Nijman, H., Sytema, S., 2013. Cause-specific mortality among patients with psychosis: disentangling the effects of age and illness duration. Psychosomatics 54 (6), 536-545.

Tidey, J.W., Miller, M.E., 2015. Smoking cessation and reduction in people with chronic mental illness. BMJ 351, h4065.

Velligan, D.I., Weiden, P.J., Sajatovic, M., Scott, J., Carpenter, D., Ross, R., Docherty, J.P., Expert Consensus Panel on Adherence Problems in Serious and Persistent Mental Illness, 2009. The expert consensus guideline series: adherence problems in patients with serious and persistent mental illness. J. Clin. Psychiatry 70 (Suppl. 4), 1-46 (quiz 47-8).

Wahlbeck, K., Westman, J., Nordentoft, M., Gissler, M., Laursen, T.M., 2011. Outcomes of nordic mental health systems: life expectancy of patients with mental disorders. Br. J. Psychiatry 199 (6), 453-458.

Walker, E.R., McGee, R.E., Druss, B.G. 2015. Mortality in mental disorders and global disease burden implications: a systematic review and meta-analysis. JAMA Psychiat. 72 (4), 334-341.

Weinstein, L.C., Stefancic, A., Cunningham, A.T., Hurley, K.E., Cabassa, L.J., Wender, R.C. 2016. Cancer screening, prevention, and treatment in people with mental illness. CA Cancer J. Clin. 66 (2), 134-151.

Wittchen, H.U., Lachner, G., Wunderlich, U., Pfister, H., 1998. Test-retest reliability of the computerized DSM-IV version of the Munich-composite international diagnostic interview (M-CIDI). Soc. Psychiatry Psychiatr. Epidemiol. 33 (11), 568-578.

World Health Organization Expert Committee, 1999. Definition, diagnosis and classification of diabetes mellitus and its complications. Report of a WHO Consultation, I: Diagnosis and Classification of Diabetes Mellitus. 